\title{
Colonização e descolonização: fundamentos da dominação Ocidental e perspectivas de transformação
}

\author{
Guilherme Lassabia de Godoy ${ }^{1}$ \\ Recebido em setembro de 2020 \\ Aceito em dezembro de 2020
}

\section{RESUMO}

Neste artigo busca-se apresentar, discutir e definir os principais termos de alguns dos debates clássicos e contemporâneos sobre colonização e perspectivas de descolonização. Esse é um tema fundamental para compreensão dos diversos impasses, conflitos e contradições do atual mundo globalizado existentes especialmente nos países que foram vítimas desse processo de dominação, mas que também são parte importante das relações sociais no chamado centro do mundo capitalista. O debate que será apresentado reflete e aponta para questões profundas da realidade social, possibilitando entender a colonialidade como uma dimensão da dominação no presente. $\mathrm{O}$ texto será dividido em dois grandes blocos que estão intrinsecamente relacionados: o primeiro discutirá mais profundamente a dominação colonial, os seus instrumentos, a sua infraestrutura e as suas consequências; o segundo apresentará diferentes perspectivas teóricas de descolonização. Os principais autores cujas reflexões guiarão o debate são: Frantz Fanon, Achille Mbembe, Edward Said, Aníbal Quijano e Lélia Gonzalez.

Palavras-chave: colonização; descolonização; raça; pós-colonial; decolonial.

\section{Colonization and decolonization: fundamentals of western domination and perspectives of transformation}

\begin{abstract}
This article seeks to present, discuss and define the main terms of some of the classic and contemporary debates about colonization and prospects for decolonization. This is a fundamental theme for understanding the various deadlocks, conflicts and contradictions of the current globalized world that exists especially in the countries that have been victims of this domination process, but which are also an important part of social relations of the so-called center of the capitalist world. The debate that will be presented reflects and points to deep questions of the social reality, making it possible to understand coloniality as a dimension of the present domination. The text will be divided into two major blocks that are intrinsically related: the first one will discuss more deeply the colonial domination, its instruments, infrastructure and consequences; the second will present different theoretical perspectives of decolonization. The main authors whose reflections will guide the debate are Frantz Fanon, Achille Mbembe, Edward Said, Aníbal Quijano and Lélia Gonzalez.
\end{abstract}

Keywords: colonization; decolonization; race; post-colonial; decolonial.

\footnotetext{
${ }^{1}$ Bacharel e licenciado em Ciências Sociais pela Universidade de São Paulo, bolsista de treinamento técnico nível III vinculado à FAPESP no projeto "O legado teórico de Waldisa Rússio para a museologia internacional”, sediado no Instituto de Estudos Brasileiros da USP. É da cidade de São Paulo, Brasil. Email: guilherme.lassabia.godoy@gmail.com
} 


\section{Introdução}

As desigualdades e conflitos sociais contemporâneos revelam a relevância de se estudar as dominações coloniais e a produção dos sujeitos subalternos do mundo moderno. Entender as consequências que a colonização e a colonialidade do poder trouxeram para a sociedade contemporânea, principalmente na produção das desigualdades fundadas nas identidades de classe, raça e gênero, é fundamental para pensar em perspectivas de transformação social. Assim, refletir e analisar em conjunto o pensamento de alguns dos grandes estudiosos sobre o tema se mostra um caminho importante para pensar nos diferentes tópicos de descolonização, as suas qualidades e seus limites, buscando a construção de uma perspectiva de descolonização para o contexto do século XXI. Avançar nos primeiros passos desse caminho é o principal objetivo deste artigo.

Para o desenvolvimento do tema faz-se necessária uma breve definição e contextualização das três correntes teóricas que guiarão o debate a seguir: a Perspectiva Anticolonial, os Estudos Pós-Coloniais Anglófonos ou Estudos Culturais e os Estudos Decoloniais. O filósofo camaronês Achille Mbembe (2014b) engloba as duas primeiras dessas três correntes no que ele chama de crítica pós-colonial - a primeira é o seu momento inaugural enquanto a segunda é seu desenvolvimento posterior - todavia, partindo da argumentação de Deivison Faustino (2015) também é possível aproximar a teoria decolonial dessa tradição.$^{2} \mathrm{~A}$ crítica pós-colonial pode ser definida como um conjunto intelectual resultante da circulação globalizada dos saberes através das diversas tradições anti-imperialistas, "um rio de múltiplos afluentes" (MBEMBE, 2017, p.68). Essa crítica, primeiramente, ilumina a ideia de que há um fosso materializado nas experiências coloniais que separa o pensamento ético europeu das suas ações, decisões e práticas políticas e simbólicas. Em segundo lugar, visa desconstruir o discurso e a representação colonial que serviram de infraestrutura ao projeto colonial, desmascarando as falsidades sem as quais não seria possível a sua realização. Nesse

\footnotetext{
${ }^{2}$ Para pensar essa questão de forma mais aprofundada ver o capítulo 2 "A disputa em torno de Fanon: uma primeira aproximação". In: FAUSTINO, 2015.
} 
sentido, a racialização do colonizado foi o principal motor dessa estrutura de mentiras e duplicidade do humanismo europeu:

Com efeito, a raça representava a região selvagem do humanismo europeu, o
seu Animal. Por conseguinte, a crítica pós-colonial tenta desarticular a
ossamenta do Animal, desemboscar as suas moradas privilegiadas. Mais
radicalmente, interroga-se: como se vive sob a égide do Animal? De que tipo
de vida se trata e de que tipo de morte se padece? [...]. Ainda mais grave, a
figura da Europa que a colônia (e, antes dela, a "plantação" sob o regime da
escravatura) vivencia e com a qual se vai familiarizando gradualmente, em
nada se assemelha à da liberdade, igualdade e fraternidade. Sob a máscara do
humanismo e do universalismo, os colonizados não desvendam apenas um
sujeito frequentemente surdo e cego. [...]. Por fim, é um sujeito para o qual a
riqueza é, sobretudo, um instrumento de exercício do direito de vida e de
morte sobre os outros, como se evocará adiante" (MBEMBE, 2014b, p. 68- 69).

Além de aproximar essas três correntes, é importante também marcar as suas diferenças e tratar cada uma segundo as suas singularidades. O Movimento Anticolonial, do qual Fanon é o maior representante neste trabalho, é composto por duas grandes dimensões entrecruzadas: as lutas de libertação nacional e as teorias marxistas de descolonização e libertação. Esse movimento foi responsável por grande parte das guerras de independência durante o século XX, especialmente no continente africano e asiático, e caracteriza-se pela defesa de revoluções nacionalistas, antirracistas e socialistas como alternativas ao colonialismo e ao imperialismo europeu-estadunidense. Dentro desse marco teórico-prático, a articulação entre raça e classe é intrínseca e forma o eixo para ação revolucionária dos condenados da terra.

A Teoria Pós-Colonial, surgida na década de 8o, rompe com a anticolonial a partir das influências pós-estruturalistas e pós-modernas presentes nas obras de intelectuais diaspóricos do universo anglófono (FAUSTINO, 2015, p.96). Apesar de não formar uma corrente única de ideias, Sérgio Costa (2006) afirma que há um consenso sobre alguns pontos que são seus pressupostos, como: desconstrução de essencialismos, crítica ao nacionalismo e às concepções dominantes de modernidade.

A abordagem pós-colonial constrói, sobre a evidência - diga-se, trivializada pelos debates entre estruturalistas e pós-estruturalistas - de que toda enunciação vem de algum lugar, sua crítica ao processo de produção do conhecimento científico que, ao privilegiar modelos e conteúdos próprios ao que se definiu como a cultura nacional nos países europeus, reproduziria, em 
outros termos, a lógica da relação colonial. Tanto as experiências de minorias sociais como os processos de transformação ocorridos nas sociedades "não ocidentais" continuariam sendo tratados a partir de suas relações de funcionalidade, semelhança ou divergência com o que se denominou centro. Assim, o prefixo "pós" na expressão pós-colonial não indica simplesmente um "depois" no sentido cronológico linear; trata-se de uma operação de reconfiguração do campo discursivo, no qual as relações hierárquicas ganham significado (Hall, 1997a). Colonial, por sua vez, vai além do colonialismo e alude a situações de opressão diversas, definidas a partir de fronteiras de gênero, étnicas ou raciais (COSTA, 2006, p.117).

Sendo uma dimensão dos Estudos Culturais, o Pensamento Pós-colonial Anglófono reflete sobre a cultura a partir da racialização realizada no contexto colonial que, acompanhando o movimento de globalização, faz-se presente no mundo inteiro, inclusive nas grandes cidades globais onde há uma crescente diáspora dos mais diversos lugares do mundo. Há dois sentidos para o prefixo pós, ele remete tanto ao que vem depois da dominação colonial, que teve fim com as independências nacionais, como a uma nova situação histórica e geopolítica "pós” pós-colonial, pois analisa um contexto globalizado em que os conflitos gerados pelo colonialismo se encontram metamorfoseados num novo cenário mundializado (FAUSTINO, 2015, p.99). Para Mbembe, o horizonte buscado por essa corrente é "um pensamento do sonho: o sonho de uma nova forma de humanismo - um humanismo crítico que, acima de tudo, assentaria na partilha daquilo que nos diferencia, aquém dos absolutos. É o sonho de uma pólis universal e mestiça” (2014b, p.71).

Já a Teoria Decolonial aparece como uma perspectiva crítica mais voltada para a América Latina, continente de origem da maioria dos estudiosos que a constituem. Nesse sentido, o termo decolonial é empregado para diferenciar sua perspectiva epistêmica das demais críticas pós-coloniais, que tem como base fundamental as experiências africanas e asiáticas (MIGNOLO, 2011; apud FAUSTINO, 2015, p. 110). Essa teoria busca radicalizar a teoria pós-colonial refletindo o mundo a partir da categoria de colonialidade. Esse conceito possui um forte potencial para pensar sobre como a dominação colonial está intrinsecamente relacionada à modernidade, seja na dimensão do poder, do ser ou do saber. Aníbal Quijano é o autor filiado a essa perspectiva teórica cuja parte da obra será discutida adiante. 
O objeto da reflexão a seguir é como alguns dos autores que estão dentro do espectro das três correntes apresentadas realizam suas críticas à dominação colonial e sugerem perspectivas de descolonização da sociedade. Assim, teremos uma visão mais ampla de como o regime colonial e a alienação racial são fundamentais e estruturantes da sociedade contemporânea e quais são as consequências disso para os problemas que enfrentamos.

\section{Colonização e a constituição de sujeitos racializados e subalternizados a partir do pensamento de Fanon e Mbembe}

Frantz Omar Fanon (1925-1961) foi um importante teórico e revolucionário Martinicano com uma curta, porém intensa biografia. Durante a $2^{\underline{a}}$ Guerra Mundial combateu pelo exército francês e em sequência formou-se psiquiatra no país, além de concomitantemente estudar profundamente as humanidades. Após terminar a sua formação, passa trabalhar como clínico na Argélia, onde tem contato cotidiano e intenso com a violência colonial. Nesse período se engaja na luta pela libertação nacional argelina (1954-62), na qual toma papel protagonista. Antes do fim da guerra adoece gravemente e em 1961, ano da sua morte, escreve uma de suas principais obras: "Os Condenados da Terra" (FAUSTINO, 2018). É importante destacar a biografia desse autor, pois ela é fundamental para a compreensão dos seus escritos e preocupações, e influi diretamente na riqueza do seu pensamento anticolonial.

A obra fanoniana descreve o contexto colonial a partir do marco de uma violência normatizada no cotidiano que se manifesta nas ações dos colonizadores e colonos que possuíam uma predisposição para cometer uma infinidade de atos cruéis que envolviam estupros, linchamentos, agressões e assassinatos (FANON, 1968). A classificação das vítimas em raças inferiores era a justificativa que legitimava tal violência. Desta forma, a dominação colonial possui um instinto genocida que sempre se materializa em massacres, ataques violentos e humilhações quando se apresentam riscos à sua continuidade. Por isso, o autor afirma que nessas sociedades não há espaço para a piedade, empatia ou qualquer sentimento humano. 
No pensamento de Fanon (1980) a dominação colonial se estabelece em um quadro de áreas geográficas determinadas e é, em sua forma mais simplificada, o assalto direto e brutal conduzido por culturas diferentes que possuíam um desenvolvimento técnico elevado, o que permitiu levar adiante essa dominação. Esse processo gera uma desculturação por parte dos nativos, consequência do estabelecimento da escravização da economia e dos corpos colonizados. Nesse contexto, o racismo aparece não como a totalidade do sistema colonial, mas como o elemento estruturante mais visível e grosseiro da opressão sistematizada de um povo sobre outro que age destruindo seus valores culturais, seus sistemas de referência do mundo e suas modalidades simbólicas de concepção de existência - procedimento realizado através da lógica da violência que possibilita a imposição da cultura europeia. Portanto, o racismo é o elemento cultural que legitima esse processo de alienação colonial: a autoridade do opressor, conquistada a partir da violência brutal, impõe ao oprimido uma forma pejorativa de ver sua cultura tradicional e original. Isso se dá de tal forma que faz com que o grupo inferiorizado enxergue sua posição como consequência direta de suas características raciais e culturais, o que possibilita uma maior facilidade de assimilação da cultura do colonizador, gerando um sentimento duplo de inferioridade e culpa (FANON, 1980).

Assim, Fanon caracteriza o racismo como elemento constituinte de uma cultura e não como uma consequência da existência de indivíduos racistas:

\begin{abstract}
A realidade é que um país colonial é um país racista. Se na Inglaterra, na Bélgica ou em França, apesar dos princípios democráticos afirmados respectivamente por estas nações, ainda há racistas, são esses racistas que, contra o conjunto do país, têm razão. Não é possível subjugar homens sem logicamente os inferiorizar de um lado a outro. E o racismo não é mais do que a explicação emocional, afetiva, algumas vezes intelectual, desta interiorização. Numa cultura com racismo, o racista é, pois, normal. [...]Ora, é preciso voltar a dizêlo, todo o grupo colonialista é racista”. Mesmo que nesse grupo exista uma minoria de membros que lutem contra racismo (FANON, 1980, p.44).
\end{abstract}

Para o autor, o sujeito racializado é produto de uma força que é totalmente exterior a si, pois em um momento inicial não é ele mesmo que elabora sua identidade racial, mas sim o europeu. Portanto, a identidade racial, apesar de não ser fruto de uma escolha do sujeito, sustenta toda sua existência e tem o poder de posicioná-lo em um lugar de submissão e inferiorização. Por isso, ser racializado significa ser constantemente 
colocado no lugar do Outro que deve sempre provar ser portador da igualdade universal da condição de humano, mas que nunca será aceito como tal. As formações racistas atuam na esfera subjetiva dos indivíduos produzindo patologias que estruturam toda sua sociabilidade, unindo a visão exterior a si racializada com os sentimentos mais interiores dos sujeitos. Como é o racista quem cria o inferiorizado, a inferiorização dos nativos é correlata à superioridade dos brancos colonizadores (FANON, 2008).

Utilizando a gramática hegeliana da luta por reconhecimento, a tese apresentada é a de que há uma impossibilidade do reconhecimento recíproco entre o colonizador/branco e colonizado/negro se realizar enquanto a dominação racial for a formação constitutiva do sujeito oprimido. O argumento é de que o reconhecimento é intersubjetivo, pois depende da relação com o outro, e a colonização é um tipo de dominação na qual a relação que se estabelece entre os dois polos é de completa dominação do colonizado pelo colonizador. Existe no negro o desejo de ser reconhecido diante do outro que o inferioriza e impede que esse desejo se concretize, essa impossibilidade faz com que o colonizado crie sua identidade partir da lente do colonizador, que o enxerga de forma redutiva à categoria desumanizadora "negro". Portanto, nesse contexto não há luta por reconhecimento uma vez que a imagem que o colonizador faz do colonizado é naturalizada por esse último. As consequências desse processo são as diversas patologias produzidas no negro durante essa dinâmica em que ele fica aprisionado ao reconhecimento do outro em uma realidade de extrema violência racial que o impede de se enxergar como humano apesar de ele ter a consciência de que o é. A aceitação da cultura e identidade do europeu/branco como legítima seria a possibilidade de obter o reconhecimento.

Nesse contexto surge uma das principais questões de Fanon em "Pele negra, Máscaras Brancas" (2008) que é entender a resposta do negro a essa realidade violenta de negação de sua humanidade: tentar se fazer branco para ser reconhecido como igual, como humano. Esse desejo de ser branco reflete o complexo de inferioridade que fundamenta as relações sociais (FANON, 2008), porém, para as estruturas racistas funcionarem esse reconhecimento não pode ser verdadeiramente efetivo: 
Lamentavelmente, para o negro, todas as tentativas de transfiguração - e, principalmente, de transgressão - de si em função da linguagem racista são frustradas pelo peso da realidade colonial: o que importa é que o negro deseje ser branco, se veja como branco e, se possível, se comporte como um, mas nunca seja, de fato, branco, a ponto de ser considerado "um de nós" (FAUSTINO, 2015 p. 72).

Assim, Fanon pensa a possibilidade de alcançar o reconhecimento recíproco a partir da luta coletiva e individual. Em sua vida isso se realizou na atividade clínica de conscientizar o inconsciente dos negros inferiorizados ao tentar transformar o desejo de se esbranquiçar em desejo de mudar as estruturas sociais; e posteriormente na sua adesão total à luta revolucionária de libertação nacional argelina. A resposta que o autor encontra é que o negro não deve viver mais o dilema de embranquecer ou desaparecer, mas deve tomar consciência de uma nova possibilidade de existir. O objetivo é atingir a conscientização da posição de inferioridade a partir da revelação e descoberta das causas desse complexo racista, tornando os oprimidos capazes de escolher a ação ou a passividade diante das estruturas sociais que originam o conflito.

Achille Mbembe, filósofo camaronês cuja teoria é muito influenciada e inspirada na obra de Fanon, pensa, de forma análoga ao martinicano, a divisão dos seres humanos no contexto colonial como um povoamento destrutivo que se dá por uma violência extrema e cotidiana em todas as esferas da vida (MBEMBE, 2017). Esse processo ocorre sob a justificativa da civilização, ou seja, é entendido como um mal necessário para desenvolver a sociedade vítima desse processo civilizador em termos capitalistas e ocidentais. Essa supremacia colonial é comparável a um estado de guerra, uma vez que a paz colonial só se diferencia da guerra, pois apenas um dos lados não tem armas. Desse confronto, os nativos saíram destruídos, já os colonizadores só saíram quando não havia nada mais para arrasar, visto que a lógica colonial segue um princípio da força, um ímpeto interno de matar e caso necessário, morrer. Como vimos, o elemento que dinamiza a estrutura da colonização é a raça. É ela que orienta os esquemas interpretativos do modo de agir e enxergar colonial (MBEMBE, 2014b).

O autor faz uma caracterização precisa do processo de racialização: ele tem como essência tornar, a partir de aspectos fenotípicos, o todo pela parte, e ao fazê-lo, produzir uma representação que é mediadora das relações na sociedade com esse todo, 
que no caso são os negros. O povoamento e o domínio colonial transformam esses processos de racialização em racismo, produzindo um outro subalterno, inferiorizado e desumanizado que passa a se submeter à realidade de precarização, exploração e espoliação capitalista, funcionando assim como uma maneira de criar uma humanidade desumana que é mais suscetível a uma exploração extrema. Ou seja, o racismo exclui e segrega o Outro racializado e o integra a partir de relações coloniais de dominação e exploração que só podem existir nesses termos por se tratar de um inferior, tornando a precariedade um atributo naturalizado do negro, podendo até mesmo ser o que o define como tal. Portanto, o racismo é uma declaração arbitrária de superioridade racial e que para se manter necessita tomar sempre novas formas através de metamorfoses (MBEMBE, 2014a).

Assim, o autor desenvolve o conceito de raça enquanto uma representação fantasmagórica, uma ficção útil, uma projeção ideológica que se remete aos traços físicos dos corpos humanos e a partir disso os hierarquiza gerando diversas catástrofes sociais como massacres e genocídios. Foi o que possibilitou que os negros tenham sido o único grupo racial humano cuja carne foi transformada em coisa e o espírito em mercadoria (MBEMBE, 2014a). Todavia, esse simulacro não ocorre apenas com os negros, mas sim com todos os rostos que são enxergados a partir de um véu que de diferentes formas os desumaniza. Dessa forma, Mbembe está tratando de relações sociais contemporâneas e complexas de grupos como imigrantes, muçulmanos, refugiados, negros, indígenas, subproletariado, entre muitos outros.

Portanto, as consequências da raça e da racialização são entendidas não apenas no contexto colonial, mas em todo contexto globalizado do neoliberalismo onde essa lógica se reproduz formando uma massa de sujeitos assujeitados, sem nenhuma categoria de cidadania ou amparo social, o que o autor chama de "devir negro do mundo" ao associar essa dinâmica com a acumulação por espoliação contemporânea. ${ }^{3}$ Esse fenômeno é consequência da ascensão da hegemonia neoliberal que fará com que quase a totalidade da população mundial se torne negra, no sentido de que as pessoas serão

\footnotetext{
3 Sobre o conceito de acumulação por espoliação e a relação com o conceito marxiano de acumulação primitiva ou originária ver HARVEY, David. Acumulação por espoliação. In: O Novo Imperialismo. Rio de Janeiro: Loyola, 2003.
} 
todas subalternas, sofrerão violências sistemáticas e viverão sob a lógica da exclusão e desamparo social total. Todos serão associados à razão negra, ou seja, a uma vivência de solubilidade e descartabilidade nas mais adversas realidades sociais (MBEMBE, 2014a).

Nesse sentido é construído o conceito de razão negra, que seria a racionalidade capaz de produzir vidas indignas e subalternas, prontas para serem dizimadas e colonizadas. São vidas que não valem nada e que por isso elas mesmas justificam as atrocidades que podem vir a acontecer a qualquer momento (MBEMBE, 2014a). Nesse ponto há uma associação com o pensamento de Fanon: o sujeito da raça é sinônimo de sujeito subalterno:

Produto de uma máquina social e técnica indissociável do capitalismo, da sua emergência e globalização, este nome [negro] foi feito para significar exclusão, embrutecimento e degradação, ou seja, um limite sempre conjurado e abominado. Humilhado e profundamente desonrado, o Negro, é na ordem da modernidade, o único de todos os humanos cuja carne foi transformada em coisa, e o espírito em mercadoria- a cripta viva do capital (MBEMBE, 2014a, p. 19-20).

\section{O Orientalismo como a invenção ocidental do Oriente e as suas consequências para o poder e dominação}

Outro autor importantíssimo no debate acerca da hegemonia mundial do poder Ocidental fundamentado pela dominação colonial é o palestino Edward Said. Sua obra "Orientalismo: O Oriente como invenção do Ocidente" (2007) é tida como um importante marco teórico para o desenvolvimento da teoria pós-colonial (MBEMBE, 2014, p.64).

O Orientalismo, em uma definição mínima, é um modo de abordar o Oriente constituído a partir de uma longa tradição que tem como elemento fundamental a centralidade de compreender esse território a partir da experiência ocidental europeia e norte-americana de forma a generalizar toda uma diversidade de povos, culturas e tradições dentro dessa categoria. Esse modo de refletir, enxergar e lidar com o mundo tem como pressuposto uma estabilidade ontológica que faz uma separação essencial do mundo entre Ocidente e Oriente. Ou seja, não considera que essas duas categorias são construídas pelo esforço humano de identificação e afirmação do Outro. 
Em uma definição um pouco mais detalhada, o Orientalismo é tanto um campo ocidental de estudos acadêmicos que engloba todos que escrevem, estudam e ensinam sobre o Oriente, como também é a instituição ocidental autorizada a lidar com essa região do mundo. Partindo dessa segunda definição, ele é uma forma ocidental para dominar, reestruturar e ter autoridade sobre o Oriente (SAID, 2007, p.29). É um discurso que tem a finalidade de representar o Oriente para o próprio Ocidente, uma vez que se parte da premissa que esses povos não são capazes de se auto representar. Portanto, é um discurso que parte da visão ocidental, representa e valora o Oriente e tem como destino o próprio Ocidente. Esse modo de representação funciona pois se acredita que o oriental/árabe não seja tão humano e civilizado quanto o ocidental, fato que justifica subjugar uma cultura inteira caracterizada como oriental. Essa lógica de invenção do Oriente funciona como uma arma fundamental uma vez que a relação Ocidente-Oriente se constituiu historicamente como relação de poder e dominação sobre o segundo polo da relação (SAID, 2007).

Essa visão orientalista parte de certos dogmas jamais questionados, como: o Ocidente e Oriente são absolutamente diferentes, o primeiro é racional, desenvolvido, humanitário e superior, enquanto o segundo é bárbaro, não desenvolvido e inferior; o Oriente é eterno, uniforme e incapaz de se autodefinir e de se auto representar, por isso é inevitável que o Oriente seja descrito por uma gramática e a partir de um olhar ocidental; O Oriente é temível por isso deve ser controlado.

Uma vez que o Oriente não foi descoberto como tal, mas sim transformado nisso a partir de representações, esse discurso, mesmo que sem intencionalidade, ao produzir um oriental que possui diferenças civilizacionais e valorativas essenciais com o europeu/norte americano, serviu como justificativa para o empreendimento e guerra colonial. Contemporaneamente, serve para legitimar o uso da violência como forma de se relacionar com esses territórios, vide as consequências humanas trágicas da ocupação imperialista e militar no Iraque, Líbia, Síria, Palestina entre outras, durante o século XXI. Porém, o Orientalismo não pode ser entendido como um corpo de mentiras contadas sobre o Oriente, mas sim como um sinal do poder ocidental sobre esse território, que se concretiza na sua intimidade com o poder político, social e econômico. Não é por acaso 
que é um discurso que permanece hegemônico por séculos. O que sustenta essa solidez é a ideia de uma identidade europeia superior à de todos os povos não europeus.

Por fim, outro ponto fundamental é que assumindo a visão de Said (2007) de que a transformação de saberes sobre o Oriente em capacidade de controle de movimentos políticos, dominação colonial e realização de missões civilizacionais do homem branco nos territórios não europeus, cumpre exatamente o oposto do que a sociedade ocidental-liberal promete. Dentro de uma cultura autoidentificada como liberal, que tem como valores fundamentais a liberdade, universalidade, igualdade, pluralidade e justiça, utilizar essa mesma gramática para legitimar o direito de julgar o Oriente nos termos do Orientalismo prova que liberdade se concretizou em nada mais que uma forma de opressão e preconceito mental (SAID, 2007, p.341). O autor propõe que a humanidade reconheça as premissas orientalistas das ações do imperialismo/colonialismo como um marco para alteração da consciência do nosso tempo, assim como o Holocausto foi reconhecido, pois, ele alimenta uma arma perigosa:

\begin{abstract}
O orientalismo constitui, assim, uma maneira de apreender o mundo, ao mesmo tempo que se consolida, historicamente, a partir da produção de conhecimentos pautados por aquela distinção binária original. [...] $\mathrm{O}$ orientalismo caracteriza, assim, um modo estabelecido e institucionalizado de produção de representações sobre uma determinada região do mundo, o qual se alimenta, se confirma e se atualiza por meio das próprias imagens e dos conhecimentos que (re)cria. O Oriente de Orientalism, ainda que remeta, vagamente, a um lugar geográfico, expressa mais propriamente uma fronteira cultural e definidora de sentido entre um nós e um eles, no interior de uma relação que produz e reproduz o outro como inferior, ao mesmo tempo em que permite definir o nós, o si mesmo, em oposição a este outro, ora representado como caricatura, ora como estereótipo e sempre como uma síntese aglutinadora de tudo aquilo que o nós não é e nem quer ser (COSTA, 2006, p.118-119).
\end{abstract}

\title{
A colonialidade como fundamento do poder e dominação nos antigos territórios coloniais
}

O sociólogo peruano Aníbal Quijano em seu artigo a "Colonialidade do poder, eurocentrismo e América Latina" (2005) destaca a chegada europeia na América como o ponto de partida de um sistema global de divisão de poder que se desenvolveu a partir de dois processos históricos que se entrelaçam. 
O primeiro é o processo de criação de uma diferenciação na ideia de raça, baseando-se em uma suposta superioridade biológica e cultural que sustenta a relação de poder entre colonizador e colonizado, definindo o branco como superior e o não branco como inferior. A difusão e aceitação dessa ideia, primeiramente pela legitimação da Igreja Católica e posteriormente pelo racismo científico, foram os principais elementos constituintes e fundantes das relações de dominação em todas as colônias a partir de uma classificação dos povos de todo o mundo nesse padrão.

O segundo é o controle de todo processo de acumulação a partir da espoliação e exploração dos recursos naturais, do trabalho e da produção pelo capital e pelo mercado mundial, formando um padrão global de controle laboral que incluía simultaneamente diferentes formas de exploração: escravidão, servidão e trabalho assalariado. Mesmo a servidão e escravidão se tratando principalmente de relações tipicamente não capitalistas de trabalho, todos esses modos de exploração formavam uma totalidade se analisadas em sua funcionalidade e em sua importância e integração no capitalismo mundial.

A articulação desses dois processos seria fundante, portanto, de uma divisão internacional e racial do trabalho e de uma estratificação racial a nível global. Nesse sentido é importante pensar como as relações de dominação colonial produziram identidades raciais: o europeu, o indígena, o negro, o amarelo e o mestiço. Por estabelecerem relações de poder entre o branco e o não branco, essas identidades produzidas foram "associadas às hierarquias, lugares e papéis sociais correspondentes, como constitutivas delas, e, consequentemente, do padrão de dominação que se impunha. Em outras palavras, raça e identidade racial foram estabelecidas como instrumentos de classificação básica da população." (QUIJANO, 2005, p.117).

É nesse ponto que os dois processos se cruzam formando uma distribuição racista do trabalho: no espaço geográfico colonial cada grupo definido por uma identidade racial foi associado a uma forma de controle e exploração do trabalho diferente em um mesmo período histórico. Forjou-se uma associação entre a suposta natureza inferior do negro com o trabalho escravo, a suposta natureza também inferior, porém mais rebelde do que a do negro dos povos indígenas, com a servidão. Ao europeu, fosse ele colono ou habitante da Europa, foram entregues os postos de administração 
colonial e o lugar do trabalho assalariado, tido como a relação universal de trabalho típica da modernidade (QUIJANO, 2005).

Portanto, para o autor o mercado mundial foi integrado a partir de uma lógica em que as diferentes formas de trabalho eram articuladas, dependentes $\mathrm{e}$ complementares. Nesse sentido a modernidade não significa a imposição do trabalho livre e assalariado, mas esse conjunto de alocações dos diferentes tipos de trabalho racialmente e geograficamente determinados em um mesmo período histórico com o objetivo de produzir para o mercado mundial capitalista.

Assim, esse padrão de dominação que serviu tão bem ao capitalismo pode ser notado não somente no microcosmo de cada território, mas também numa perspectiva das relações internacionais em que os países centrais, compostos majoritariamente por brancos, estão associados ao trabalho assalariado. Os países da semi-periferia por sua vez possuem uma base de trabalho assalariada, mas ainda com informalidade e precarização, são compostos por brancos, negros, indígenas e mestiços, mas sempre com os brancos ocupando as posições superiores às demais identidades. Por fim, os países periféricos, onde se concentram as formas de exploração mais violentas e ainda persistem com alta ocorrência a escravidão, servidão e economia de subsistência, são compostos majoritariamente por não brancos.

Esse padrão imposto de forma sistemática por todo globo resultou em uma naturalização da divisão racial do trabalho que se expressa até os dias de hoje. As relações de produção no mundo inteiro continuam sendo determinadas pelo eixo racial. Não é uma coincidência que as formas de trabalho não pagas sejam ainda quase que uma exclusividade dos países de composição racial não branca e que mesmo nas realidades nacionais, a relação tipicamente capitalista de produção seja concentrada para a parte branca da população. Essa colonialidade do poder também se apresenta nos salários e posições inferiores na estratificação social dos não brancos em todo o mundo. Foi essa colonialidade do controle do trabalho que garantiu à Europa o posto de centro do mundo capitalista ao possibilitar a classificação do mundo inteiro a partir da lógica racialcolonial e impor sua cultura, subjetividade e conhecimento através do processo violento e repressor de colonização, formando uma ordem cultural global baseada no eurocentrismo (QUIJANO, 2005). 
Assim, um dos principais desafios levantados por Quijano para a periferia global é romper com a ideia eurocêntrica de que todos os países não-europeus são préeuropeus, ou seja, estão no caminho da sequência histórica de se modernizar e um dia alcançar a Europa. Essa forma de enxergar o mundo opera formando um espelho que distorce a imagem que reflete. Ao se ver a partir desse reflexo, esses países se deparam com uma imagem de si que não corresponde à realidade e, por isso não conseguem diagnosticar os verdadeiros conflitos e propor soluções que efetivamente funcionem.

O autor discute como esse espelho opera em relação à questão nacional e na formação dos estados nacionais na América Latina. O Estado-Nação é definido como uma sociedade nacionalizada politicamente organizada por um Estado, o que implica necessariamente em instituições modernas e democracia política. A democracia é parte essencial uma vez que todo processo de nacionalização nos tempos modernos se deu a partir de uma limitada, mas real, democratização da sociedade. Foram processos de consolidação da cidadania como direito de igualdade civil, política e legal para pessoas desigualmente localizadas no processo de distribuição de recursos e bens que garantiram essa democratização. Esse processo também é importante, pois estabelece uma identidade comum aos cidadãos, formando uma comunidade imaginada que expressa sua identidade comum justamente na participação política efetiva e democrática no processo de distribuição e controle do poder.

No continente latino-americano o processo de formação dos Estados Nacionais se deu a partir de uma homogeneização social pensada a partir da visão eurocêntrica de mundo, o que ocorreu não por meio da integração democrática de todos os cidadãos, mas sim pela exclusão e eliminação de parte significativa deles: os negros, indígenas e mestiços. Segundo Quijano, essa condição é determinante para concluir os porquês da democracia latino-americana ser tão frágil e os porquês da colonialidade do poder se manter como mediadora da distribuição dos poderes na América Latina. Assim, nessas regiões o Estado é independente, mas as sociedades permanecem coloniais, pois os processos de independência levaram a uma metamorfose da colonialidade do poder sob novas bases institucionais. 


\section{Perspectivas de descolonização: estudos pós-coloniais, decoloniais e lutas anticoloniais. Como sair da grande noite?}

Além de analisar os problemas e efetuar duras críticas ao empreendimento colonial, a colonialidade do poder, a dominação racial, ou no que se pode sintetizar como os fundamentos da dominação ocidental, os autores cujo pensamento tentamos expor na parte anterior do artigo também apontaram algumas possibilidades de saída, de descolonização da sociedade.

Fanon e Mbembe definem a África como ponto de partida para o futuro, como o espaço do novo, da criação de uma nova dimensão e possibilidade civilizacional que pode transformar o mundo da morte no mundo da vida. Na obra de ambos se discute a teoria da morte, que é a realidade colonial e neocolonial, porém, pretende-se chegar na teoria da vida, de uma sociedade verdadeiramente universalizada. Um ponto importante nesse caminho é a memória. No seguinte trecho, Mbembe (2017) sintetiza muito bem seu papel durante o processo de descolonização:

\footnotetext{
No ensaio é apontado que toda memória colonial, composta por uma história de sangue, massacres e talvez de alguns dos episódios mais horríveis do mundo moderno, deve ser tratado como memória comum do mundo inteiro, e não apenas dos participantes diretos da história. Se for vista como uma questão que envolve certos grupos e não a Humanidade inteira, a lógica segregacionista que baseia as relações do presente e baseou as do passado vai se manter hegemônica: "Enquanto formos incapazes de assumir memórias de Todo o Mundo, será impossível imaginar um mundo comum e uma humanidade verdadeiramente universal (Ibidem, p.168).
}

Para ambos a descolonização como acontecimento histórico é um momento de transição da modernidade tardia: busca se apropriar dos valores da modernidade e transnacionalizá-los. Enquanto a colonização impedia qualquer forma de pertencimento ao impossibilitar a identidade e cidadania do colonizado e, ao mesmo tempo destruía a cultura local, a descolonização tem como foco principal abrir o mundo no sentido de abrir algo novo que anteriormente estava enclausurado, desabrochando e possibilitando ao colonizado criar, modificar, habitar e pertencer ao mundo (MBEMBE, 2014b).

Como vimos, Fanon procurava entender e acabar com o complexo de inferioridade do negro gerado pelas relações coloniais. O propósito de sua obra é buscar 
os caminhos para libertar os povos colonizados da alienação que lhes foi imposta e conseguir realizar um encontro saudável entre o negro e o branco. O pressuposto para isso é que a luta antirracista deve ser luta pela igualdade universal, pelo fim da concepção a partir da qual a cor de pele produz inferioridade ou qualquer diferença essencialmente racial. Isso sugere uma ruptura com a ideia de raça, ou seja, a abolição da raça como elemento de diferenciação entre seres humanos, o que só se pode realizar quando se tornar verdade que o negro é um ser humano igual ao branco e quando o negro for reconhecido como apenas um homem entre outros homens. A similaridade entre os homens e uma cidadania universal é o princípio fundamental para a realização da abertura do mundo, ou seja, o objetivo da luta pela descolonização e pela autonomia humana4 (FANON, 1980). Vale destacar que a afirmação estratégica da identidade racial de forma positiva é parte importante desse processo, não como a finalidade, mas um dos meios para se se lutar contra a dominação racial e se alcançar a emancipação.

Para Fanon o reconhecimento universal só seria possível quando as condições da dominação colonial fossem destruídas. Em seu pensamento, as únicas forças capazes de vencer o racismo e a alienação colonial são as lutas radicais, revolucionárias e emancipatórias de descolonização. Em seu contexto histórico essas lutas foram concretizadas nos movimentos anticoloniais de libertação nacional, dos quais o autor foi um grande defensor e participante, principalmente no contexto argelino.

Assim, a questão para Fanon não é modernizar a sociedade, pois esse projeto significaria o povoamento destrutivo que o colonizador exerce através de relações estruturadas na dominação racista. A questão, na realidade, é partir de uma resolução violenta positiva (no sentido de criar o novo) que reinvente o futuro de todas colônias e ex-colônias, sendo capaz de transformar e resolver as tensões do presente - sair da grande noite é a metáfora desse momento histórico para o martinicano (FANON, 1968).

Segundo Mbembe (2014a), as questões que Fanon coloca são pertinentes na contemporaneidade, pois apesar de o nosso mundo não ser o mesmo que o dele, também não é outro, uma vez que a colonialidade do poder é estruturante da realidade social. Sair da grande noite exigiria uma ação consciente de provincializar a Europa, ou seja,

\footnotetext{
${ }^{4}$ Essas ideias estão mais desenvolvidas no ensaio: FANON, Frantz. Racismo e Cultura. In: Defesa de Revolução Africana. Lisboa: Livraria Sá da Costa Editora, 1980.
} 
retirá-la do lugar a ser seguido e do centro ao redor do qual resto do mundo deve girar, pois, essa Europa que fala tanto do homem universal ao mesmo tempo, o massacra em todos os cantos do mundo.

No raciocínio de Fanon, para sair da realidade colonial é necessário o processo pelo qual o colonizado passa a falar por si em primeira pessoa, apropriando-se do seu eu, o que não tem a finalidade apenas de despertar a autoconsciência individual, mas sim a ascensão da humanidade, a abertura do mundo. Essa tomada de consciência se inicia com uma retomada crítica e dinâmica da cultura tradicional pelo colonizado. Ela é o motor da consciência dos oprimidos, uma vez que permite a identificação dos inimigos e dos porquês das opressões sofridas, possibilitando a geração de uma revolta que, se organizada na forma de luta pela libertação nacional, seria capaz de gerar a consciência nacional e a efetivação do projeto descolonizador que garantisse o real poder democrático para todos (FANON, 1968), condição necessária para a formação de Estados-Nação como vimos na teoria de Quijano.

Dentro de um contexto em que a colonialidade do poder é a regra, há uma violência desmedida cometida pelo colonizador direcionada ao colonizado, trata-se de uma realidade tão violenta que esvazia o passado e restringe as possibilidades de futuro do oprimido, é uma sistemática fábrica de feridas. Já a violência vinda do colonizado tem início como uma reação espontânea e individual contra essa realidade de insuportável sofrimento, mas aos poucos ela se torna uma reação coletiva que ressignifica o mundo com o objetivo de produzir vida, ou seja, produzir transformações, e assim, o que era uma insurreição se torna um processo revolucionário. A linguagem da colonização sempre foi a violência e o não o reconhecimento, logo essa violência é a resposta à sociedade e a única possibilidade de sua transformação e destruição, afinal não há possibilidade de comunhão em uma sociedade que se define por ser compartida, fragmentada. Além disso, essa violência tem a potencialidade de criar laços nacionais, pois mobiliza os colonizados em torno da luta por sua libertação, gerando uma consciência e identidade nacional, porque passam a se reconhecer como agentes da história e do destino em comum, o que facilita o passo seguinte, a construção de um Estado-nação. Ou seja, a violência é fruto de um processo de libertação nacional gerador de consciência (FANON, 1968). 
Para Mbembe (2017), o conceito de violência de Fanon tem uma dimensão tanto política quanto clínica, pois pela violência realizada em vez de sofrida, o colonizado percebe-se em pé de igualdade com o colonizador, passando por um processo de recuperação, requalificação e reaprendizagem sobre si que implica em uma cura individual e em uma cura política, coletiva. Logo a descolonização modifica fundamentalmente o ser, ela humaniza, cria homens novos pelo processo que os liberta.

A violência, portanto, possui o papel de poder instituinte de uma nova ordem social que surja dos escombros da antiga realidade colonial produtora de dor, sofrimento, medo e morte. Logo ela só faz sentido se pensada dentro de um processo de elevação da humanidade, que permita transformar a realidade de subjugação colonial e racial em uma realidade na qual haja a possibilidade de diálogo entre iguais, na qual existam as condições para a realização do reconhecimento recíproco:

\footnotetext{
A cultura espasmada e rígida do ocupante, liberta, oferece-se finalmente à cultura do povo tornado realmente irmão. As duas culturas podem enfrentarse, enriquecer-se. Em conclusão, a universalidade reside nesta decisão de assumir o relativismo recíproco de culturas diferentes, uma vez excluído irreversivelmente o estatuto colonial (FANON, 198o, p.48).
}

Nessa mesma linha, para Mbembe (2014b) a condição de realização da descolonização na África é a real democratização dessas sociedades protagonizada pelos próprios povos do continente. Porém, o autor destaca a necessidade de uma solidariedade internacional de todos no mundo que acreditam que sem o reconhecimento da humanidade do continente africano e sem a redenção dos povos desse continente, o mundo permanecerá pobre em seu espírito. Nesse processo a importância da construção do futuro a partir do enaltecimento da memória e a busca a partir dela do reconhecimento da humanidade do Outro, são a condição para que o futuro se realize de forma diferente. $O$ esquecimento não leva a superação, assim como o uso da violência defendido por Fanon deve ser ponderado a partir das experiências passadas.

Na concepção de Quijano, a situação colonial persiste nas sociedades atuais, pois não houve a construção de nenhum Estado-Nação na América Latina que tenha conseguido se impor contra a colonialidade do poder, objetivo que exigiria um processo 
de democratização que descolonizasse as relações sociais, culturais e políticas entre as raças. $\mathrm{O}$ fator determinante para isso foi que a nação se constituiu justamente contra os interesses dos não brancos e continua sendo expressão direta da colonialidade do poder contra a maioria da população. A vigência da dominação racial gerada pela colonialidade do poder impede que haja possibilidades de construção de Estados-Nação democráticos, pois a sociedade se mantém organizada em estruturas coloniais.

Portanto, o autor segue de certa forma a mesma trilha de Fanon e Mbembe e propõe que a existência de um Estado-nação democrático na América Latina só é possível a partir de um processo revolucionário que consiga se impor à colonialidade do poder e seu eixo principal, a dominação racial, através de uma democratização que garanta uma redistribuição do poder para massa não branca excluída.

Costa (2006) defende que o processo de descolonização não se dê nos termos do debate essencialista que, como vimos com o exemplo do Orientalismo, define ontologicamente diferenças entre a identidade branca europeia-estadunidense e toda a outra parte do mundo na tentativa de destruir as fronteiras erguidas, visão que dialoga profundamente com o que propõe Mbembe:

[...] os estudos pós-coloniais buscam alternativas para a desconstrução da antinomia West/Rest que sejam distintas da simples inversão do lugar da enunciação colonial. Trata-se, portanto, não de dar voz ao oprimido, mas [...] de uma descolonização da imaginação o que implica uma crítica que não seja simplesmente anticolonialista, uma vez que, historicamente, o combate ao colonialismo teria se dado ainda no marco epistemológico colonial, por meio da reificação e do congelamento da suposta diferença do colonizado em construções nativistas e nacionalistas. O pós-colonialismo deve promover precisamente a desconstrução desses essencialismos, diluindo as fronteiras culturais legadas tanto pelo colonialismo como pelas lutas anticoloniais (COSTA, 2006, p.120-121).

Lélia Gonzalez, autora pioneira na discussão acerca da interseccionalidade, faz a crítica à dominação colonial e suas heranças a partir da perspectiva do feminismo negro latino-americano e buscando essa descolonização da imaginação. A autora defende que nesse contexto as lutas feministas devem partir do pressuposto de que estão em sociedades multirraciais e pluriculturais, afastando-se de visões eurocêntricas e neocolonialistas. Assim, há uma impossibilidade de tentar refletir sobre a discriminação da mulher sem pensar em suas articulações com a raça, pois sem essa articulação o 
feminismo cairá em um falso discurso universalizante abstrato muito similar ao discurso dominante. Na realidade local falar de processos discriminatórios e de exclusão contra mulheres e não tratar da questão racial é ignorar que grande parte dessas mulheres são não-brancas (GONZALEZ, 2018).

Para Gonzalez (2018) uma das principais formas na qual o racismo se manifesta no Brasil e na América Latina é negando o papel central da cultura negra e africana para a formação histórico-cultural. Contra essa lógica, a autora evoca a categoria de amefricanidade para pensar a contribuição fundamental dos povos negros e indígenas na formação cultural do continente, categoria que surge com o intuito de ultrapassar qualquer barreira cultural, territorial e ideológica. Além disso, sendo os povos do continente vítimas da dominação colonial e racista que, através da violência, busca legitimar a superioridade dos brancos e naturalizar a exclusão dos não-brancos, gerando uma destituição de todo seu legado cultural e histórico, a herança africana deve ser uma fonte vivificadora de força para a resistência e transformação. Assim, assumindo a amefricanidade é possível contribuir para um mundo pan-africano a partir da atuação na diáspora e superando uma visão idílica e ultrapassada da África, uma vez que a amefricanidade se expressava nas resistências culturais, revoltas de pessoas escravizadas na construção de formas de sociedades livres por todo continente, como os quilombos. Nas palavras de Gonzalez: “[a amefricanidade] é, em última instância, reconhecer um gigantesco trabalho de dinâmica cultural que não nos leva para o outro lado do Atlântico, mas que nos traz de lá e nos transforma no que somos hoje, amefricanos" (GONZALEZ, 2018, p.333).

\section{Considerações Finais}

É certo que projetos políticos alternativos ao mundo pautado pela colonialidade do poder buscam uma verdadeira descolonização, a construção de uma humanidade que cumpra efetivamente os princípios da universalidade, autodeterminação e igualdade entre os povos e têm muito a absorver dos diversos pensamentos apresentados. Na mesma medida, todas as correntes que formam a crítica pós-colonial e anticolonial têm um valor epistemológico importante para qualquer movimento que busque a superação 
dos elementos coloniais que são a base de grande parte das desigualdades do mundo contemporâneo.

Nesse sentido, é possível reivindicar as respostas e o legado de Fanon para os desafios das lutas de hoje, uma vez que a diferença entre o mundo atual e o de Fanon é mais de intensidade do que de espécie, pois as principais contradições continuam as mesmas, mas hoje não há uma resposta à altura das lutas de libertação do século XX (FAUSTINO, 2018, p.125). Dessa forma, a contribuição teórica e prática do martinicano para pensar em uma clínica do sujeito e da sociedade na atualidade é de grande valor. Pensando também na continuidade dos conflitos estruturais que se reproduzem no presente e que têm origem na dominação colonial e na consolidação do capitalismo global, Quijano (2005) opera o conceito colonialidade do poder como chave para entender e superar a sociedade fundada na violência e exclusão, consolidando uma verdadeira democracia. Parte desse processo de "saída da grade noite" é o desafio colocado por Said (2007) de diluição dos essencialismos criados durante a dominação colonial que formam o imaginário e as categorias de representação do Outro não ocidental. Sem que haja uma ruptura com essas ideias que se materializam em práticas de violência, discriminação, espoliação, exploração e exclusão não há como existir o reconhecimento de uma humanidade em comum, como afirma Mbembe. Já para o desenvolvimento de uma identidade e um imaginário descolonizado, Lélia Gonzales aponta para a afirmação da identidade amefricana pelos movimentos sociais como forma de explicitar a fundamentalidade da cultura negra, africana e indígena para toda dinâmica cultural latino-americana, além de recuperar o legado de toda resistência dos povos negros e originários contra a dominação colonial.

Portanto, a partir das diversas reflexões dos autores cujas ideias foram abordadas no artigo fica evidente que o caráter colonial da atual dominação ocidentalbranca apresenta múltiplas faces e é essencial para a manutenção das desigualdades de redistribuição e de reconhecimento que se materializam em processos de injustiça social, violência e exclusão. Apesar das divergências existentes entre as perspectivas apresentadas, é consenso entre elas a crítica ao projeto universalista da modernidade que, contraditoriamente, se realizou a partir de processos de violência e exclusão de grande parte dos habitantes do mundo, sobretudo aqueles que viviam nas colônias, 
usando a falsa justificativa de superioridade racial. A continuidade desses processos no mundo pós-colonial é um dos elementos que possibilita o entendimento da colonialidade como dimensão da dominação de classe, raça e gênero do presente, que ocorre a partir de novas políticas, práticas e representações, gerando uma dominação que ainda é colonial, mas metamorfoseada. Investigar a fundo a colonialidade atual e pensar a partir das experiências e pensamentos descolonizantes é uma tarefa fundamental para enfrentar os desafios que o século XXI apresenta. Só a partir da cicatrização dessas feridas coloniais é possível pensar na construção de uma sociedade que radicalize e realize de fato as promessas da modernidade de um mundo justo, igualitário e livre.

\section{Referências}

BRAUDEL, Fernand. A dinâmica do capitalismo. Rio de Janeiro, Ed. Rocco, 1987.

CARDOSO, Cláudia Pons. Amefricanizando o feminismo: o pensamento de Lélia Gonzalez. In: Revista Estudos Feministas, Florianópolis, v. 22, n. 3, p. 965-986, set. 2014. ISSN 1806-9584. Disponível em: <https://periodicos.ufsc.br/index.php/ref/article/view/36757>.

COSTA, Sérgio. Desprovincializando a sociologia: a contribuição pós-colonial. In: Rev. bras. Ci. Soc. [online]. 20o6, vol.21, n.6o, pp.117-134.

FANON, Frantz. Em defesa da revolução africana. Lisboa: Livraria Sá da Costa Editora, 1980.

. Os condenados da terra. Rio de Janeiro: Civilização Brasileira, 1968.

. Pele negra, máscaras brancas. Salvador: EdUfba, 2008.

FAUSTINO, Deivison. Frantz Fanon um revolucionário particularmente negro. São Paulo: Ciclo Editorial, 2018.

Por que Fanon? Por que agora? Fanon e os fanonismos no Brasil. 2015. 261 f. Tese (Doutorado em Sociologia). Universidade Federal de São Carlos, São Carlos, 2015.

GONZALEZ, Lélia. Lélia Gonzalez: primavera para as rosas negras. São Paulo: UCPA Editora, 2018. 
QUIJANO, Aníbal. Colonialidade do poder, eurocentrismo e América Latina. In: Edgardo Lander (comp.) A colonialidade do saber: eurocentrismo e ciências sociais. Perspectivas latinoamericanas. CLACSO, Buenos Aires, 2005.

MBEMBE, Achille. A farmácia de Fanon. In: Políticas da inimizade. Lisboa: Antígona, 2017.

Crítica da razão negra. Lisboa: Antígona, 2014a.

. Sair da Grande Noite: ensaios sobre a África descolonizada. Luanda: Edições Mulemba da Faculdade de Ciências Sociais da Universidade Agostinho Neto, 2014b.

MIGNOLO, Walter. The Darker Side of Western Modernity: Global Futures, Decolonial Options. Durham: Duke UP, 2011.

SAID, Edward. Orientalismo: o Oriente como invenção do Ocidente. São Paulo: Companhia de Bolso, 2007. 